\title{
A Survey on the Skills Necessary for Effective Orientation Professionals
}

\author{
Tony W. Cawthon and Jeanine A. Ward-Roof
}

\begin{abstract}
A survey was distributed using the National Orientation Directors Association's (NODAnet) Listserve asking participants to Identify skills that are necessary for a professional to be effective in the field of orientation. The most commonly reported were organizational skills, human relations skills, flexibility, creativity, vision, and administrative knowledge. Each of these skills and their implications for the orientation professional are discussed.
\end{abstract}

Orientation has a long history of importance within higher education (Rentz \& Associates, 1996) and, like most other student affairs functions, faculty administered early orientation programs. As the institution of higher education matured, student affairs and the specific function of orientation developed,

The Council for the Advancement of Standards in Higher Education (CAS): The Book of Professional Standards for Higher Education (1997) states that orientation is "... an important tool for improving student retention" (p. 132), and that it will continue to be important in student retention. However, little research exists on the orientation professional and the role that person plays in retention efforts. Therefore, this study focuses on issues related to the orientation professional, specifically on the new professionals in the field, and the skills one needs to be successful.

Most student affairs professionals directing orientation programs are entry-level, new professionals. (Mullendore \& Abraham, 1993). Rentz and Associates (1996) indicate that in order to establish purposeful interventions within the lives of students, an orientation professional must develop a strong foundation of skills to include communication, programming, leadership, and administration. Additionally, Rentz and Associates (1996) state that an orientation professional, in order to be effective, must be able to balance theory and practice as well as understand the culture of today's students. In addition, Mullendore and Abraham (1993) state that the skills important to new professionals in orientation include the ability to perform a multitude of tasks, delegate, pay attention to detail, work with students, remain enthusiastic, coordinate multiple projects, and be perceived as competent within and outside of the university community.

Coleman and Johnson (1990) define new professionals as recent graduates, professionals within the first five years of their student affairs full-time work experience, or professionals who have been out of the field or entered into a new facet of the student affairs profession. This definition will be used in the context of this article.

Tony W. Cawthon, Ph.D., is an Assistant Professor of Counseling and Educational Leadership at Clemson University. cawthot@clemson.edu

Jeanine A. Ward-Roof, is Director of Orientation, Leadership and Disability Services at Clemson University. wjeanin@clemson.edu 


\section{Method}

\section{Subjects and Research Procedures}

For the purpose of this study, the researchers developed distributed a survey to all participants on the National Orientation Directors Association (NODAnet) listserve. The instrument asked a variety of questions including institution type of current employment, percentage of time spent in orientation, years in the orientation field, reasons why individuals selected the orientation field, skills believed desirable for orientation coordinators, and the career path individuals took to their current positions. The survey included both open-ended and forced-response questions. The recipients responded voluntarily to the survey by e-mailing their answers to the researchers.

\section{Results}

A total of 43 usable email responses was returned from professionals. Some respondents completed all of the questions while others answered selected questions; thus, total responses may not equal the total number of respondents and percentages.

Of the 43 respondents, $39 \%$ classified their institutions as four-year private colleges or universities; $57 \%$ classified their institutions as four-year public colleges or universities; and 4\% classified their institutions as two-year public colleges. There were no respondents from a two-year private college. Additionally, 59\% indicated that their institution size was between 5,000 and 10,000; $9 \%$ indicated their institution size was 10,000-15,000; and 32\% responded that they worked at institutions enrolling over 15,000 students. Fifty six percent of the campuses were described as urban or suburban and $44 \%$ were described as rural; $74 \%$ were described as residential and $26 \%$ as commuter campuses.

Additional data collected included reporting structure and the highest degree attained by the respondents. The majority of respondents, $76 \%$, indicated the orientation professional reported to student affairs. Twelve percent of the respondents indicated a reporting line to academic affairs and the remaining $12 \%$ of the respondents indicated reporting to neither area. The highest degree attained varied widely, with most respondents $(77 \%)$ having obtained a master's degree. Sixteen percent of the respondents indicated their highest degree attained was a bachelor's degree and $4 \%$ indicated they had completed the doctorate.

Data describing the years of experience and percentage of time in orientation was also collected. The respondents indicated a range of experience from four months to 20 years, with the majority (88\%) citing less than five years experience. All but $5 \%$ of the respondents stated that orientation was only one of the duties they were responsible for administering (full-time, 5\%; part-time, 95\%). Of the respondents who indicated part-time orientation responsibilities, $22.5 \%$ indicated $75 \%-100 \%$ of their work responsibilities were orientation-related, $32.5 \%$ indicated $50 \%-74 \%$ of their time; $20 \%$ indicated $30 \%-49 \%$ of their time; and $25 \%$ indicated that less than $30 \%$ of their responsibilities was in orientation. 
When asked why they chose to work in Orientation, the respondents' answers varied greatly. However, the responses can be categorized in three specific areas. Thirty-sevenand-a-half-percent of the respondents chose the orientation field because they enjoyed the job duties, while $35 \%$ specifically sought an orientation position because of a mentor relationship or prior experience in orientation, and $27.5 \%$ inherited or were assigned the orientation responsibilities.

The respondents identified numerous skills they believed an orientation professional need to possess to be effective. The top seven skills were organizational skills (26.8\%), communication skills (14.1\%), human relations skills $(12.7 \%)$, flexibility $(12,7 \%)$, creativity (11.3\%), vision (11.3\%), and administrative knowledge (11.3\%). Other skills identified include a desire to work with students, humor, endurance, patience, motivation, problem solving, and the knowledge and application of student development theory.

\section{Limitations}

Since this survey looks at broad practical implications, limitations regarding the generalizability are inevitable. The sample size is small and the participants were not selected randomly, as participation was based on self-selection. The prudent researcher also will note that not all orientation professionals are on the listserve and might not have had the opportunity to respond. Finally, all respondents did not answer all of the questions.

\section{Discussion}

The survey results highlight numerous skills the respondents felt were needed by orientation professionals. The results indicate that individuals need a multitude of skills in order to be effective in the field. A brief discussion of each skill identified by the respondents' follows.

\section{Organizational Skills}

The demands of implementing a multi-faceted orientation program, regardless of institutional size, require, by necessity, strong organizational skills. The respondents of this survey indicated that organizational skills include planning and coordinating various aspects of programming and staff supervision, managing details, coping with the difficult workload of orientation implementation, and establishing priorities. Without organizational skills, according to the respondents, orientation professionals would have difficulty fulfilling their roles.

\section{Human Relationship Skills}

In any aspect of student affairs, human relations skills are essential. An orientation director who does not utilize human relationship skills risks losing valuable components 
from the campus-wide program. Survey respondents defined human relations as:

- working with staff, new students, and parents;

- possessing the ability to communicate effectively;

- establishing cooperative relationships;

- coordinating diverse groups that are essential to the implementation of the university-wide program;

- being willing to listen to and work with those wanting input into the orientation program;

- informing supervisors of critical issues; and

- being a skilled negotiator and diplomat.

An orientation director has numerous responsibilities as well as a short timeframe to complete the tasks. According to Rentz and Associates (1996), a director must utilize large numbers of volunteer or paid student employees in order to coordinate a successful program. The orientation director must successfully supervise this large group in order to be effective, and human relations skills are therefore critical.

\section{Flexibility}

The need for flexibility is universal in all areas of student affairs. As students continue to change, so do their needs and desires. The job of an orientation professional is to anticipate these changes in order to meet the evolving needs of students and to incorporate them into the orientation program. The respondents defined the term flexibility as being dedicated to the institution, balancing current trends with campus traditions, and responding to unanticipated challenges in order to create a strong vehicle for orienting new students and their parents.

\section{Creativity}

Many new orientation professionals have little opportunity to revise the programs they are given. When orientation programs lack creativity, it is often because of the difficulty in making small changes within traditional campus organizational structures. Respondents defined creativity as enthusiasm, energy, motivation, and a sense of humor, and they considered creativity necessary for long-term survival in the field or orientation. While some new professionals will not be able to initially make sweeping changes in the overall program, creativity can enhance the training of staff, development of themes and printed materials, planning of videos and other multi-media presentations, and coordinating various other aspects of the program. As these initiatives become successful, more opportunities are afforded the director.

\section{Administrative Knowledge}

In order to implement an orientation program successfully, a professional must have 
ample administrative skills and knowledge of the campus. These were defined by respondents as the ability to delegate, facilitate, mediate, and network; patience; public relations skills; written and oral communication skills; and knowledge of time-honored campus traditions. The respondents felt that an orientation professional could have great difficulty operating a program at any institution without an understanding of campus history and current administrative leadership.

Vision

Vision is a necessary ingredient for an orientation director in designing a program that meets changing student needs. When the opportunity for change or future planning arises, the professional with a well-defined long-range vision will be able to plan for the future of the program. While vision takes time to develop, share, and especially implement, it can be a source of renewed enthusiasm and sense of accomplishment for the profession.

\section{Summary}

The research indicates that a professional entering the field of orientation needs to possess a myriad of skills. Many of these skills are taught in most student personnel preparation programs. In addition, individuals often learn the basics of these skills within undergraduate and graduate student leadership positions, in training experiences, by involvement with professional associations, or by establishing an effective mentoring relationship with a seasoned orientation professional. As the orientation field evolves and future studies are conducted, additional skills may be identified as necessary for ensuring effectiveness as an orientation professional.

\section{References}

Coleman, D. D., \& Johnson, J. E. (1990). The new professional. In D. D. Coleman \& J. E. Johnson (Eds.), The new professional: A resource guide for new student affairs professionals and their supervisors. (1-16). (NASPA Monograph Series, Vol. 10). Washington: Author.

Council for the Advancement of Standards for Higher Education. (1997). Student orientation standards and guidelines. Washington: Author.

Mullendore, R. H., \& Abraham, J. (1993). Organization and administration of orientation programs. In M. Lee Upcraft, Richard H. Mullendore, Betsy Barefoot, \& Dorothy Fidler (Eds,), Designing successful transitions: A guide for orienting students to college (61-77). Columbia, SC: The National Resource Center for the Freshmen Year Experience.

Rentz, A, L., \& Associates. (1996). Student affairs practice in higher education. San Francisco: Jossey-Bass. 